\title{
Identification of mental barriers in the implementation of cloud computing in the SMEs in Poland
}

\author{
Dorota Jelonek, Cezary Stępniak, Tomasz Turek, Leszek Ziora \\ Faculty of Management, Czestochowa University of Technology, \\ Al. Armii Krajowej 19B, 42-200 Czestochowa, Poland \\ Email: jelonek@zim.pcz.pl; cstep@zim.pcz.pl; turek@zim.pcz.pl; ziora@gazeta.pl
}

\begin{abstract}
Cloud computing is an emerging new computing paradigm designed to deliver numerous computing services through networked media such as the Internet. This solution offers many possibilities that did not exist before for all enterprises but especially for small and medium sized companies, which very often cannot afford for huge investments in contemporary IT solutions. The aim of the paper is an attempt of barriers identification especially mental barriers of managers which hinder making decision concerning implementation of cloud computing in small and medium sized companies in Poland. In the paper the notion of cloud computing was presented as well as benefits in the aspects of: technical, financial, organizational ones and barriers of cloud computing adoption. Next the results of research conducted in Polish SMEs companies were presented. The research showed that the biggest mental barriers perceived by managers concern lack of trust, incomplete knowledge about cloud computing and not perceiving necessity of changes in currently used IT model.
\end{abstract}

\section{INTRODUCTION}

$\mathrm{C}$ LOUD computing is currently the fastest growing IT service. This approach offers several advantages to potential users such as "metered" use (i.e., pay-as-you-go) which offers scalability, online delivery of software and virtual hardware services (e.g., collaboration programs, virtual servers, virtual storage devices) which would enable organizations to obviate the need to own, maintain and update their software and hardware infrastructures. The flexibility of this emerging computing service has opened many possibilities for organizations that did not exist before. Among those organizations are those engaged in healthcare provision.

Cloud Computing for many years has been mentioned among the most important trends of IT development. According to Forrester report the global market of Cloud Computing services in 2011 was 40,7 billion USD [1] and prognoses tell that in 2020 this market will grow to assessment value of 241 billion USD, it is six times.

The literature review reveals that many studies were and currently are being conducted on the use of cloud computing by large scale enterprises primarily on their perceptions about cost reduction, ease of use and convenience.

Cloud computing is adopted by enterprises [2],[3], public sector [4], eGovernment [5], regional business community [6], for education [7], for healthcare provision [8] and many other organizations.
The literature review reveals that many studies were and currently are being conducted on the use of cloud computing by large scale enterprises primarily on their perceptions about cost reduction, ease of use and convenience, reliability, sharing and collaboration and lastly but not the least, security and privacy [2], [9]. Large enterprises have quickly adopted this model of IT resources management [2] but among SMEs companies it is more and more often used solution [10], [3], [11]. The importance of cloud computing parameters on SMEs adoption in a large degree convergent with perspective of big companies e.g. King [3] indicated that the cost reduction, avoiding natural disaster mishaps, better security but lack of reliability in using cloud computing are the most important parameters. On the other hand Gupta et al [10] indicated that for SMEs companies which want to implement cloud computing model the most important are such factors as: ease of use and convenience which is the biggest favorable factor followed by security and privacy and then comes the cost reduction. The fourth factor reliability is ignored as SMEs do not consider cloud as reliable. Last but not least, SMEs do not want to use cloud for sharing and collaboration and prefer their old conventional methods for sharing and collaborating with their stakeholders [10].

The aim of this paper is to identify mental barriers in implementation of cloud computing in SMEs in Poland. There were proposed considerations of mental barriers from the perspective of: lack of trust, incomplete knowledge on cloud computing and not perceiving necessity of changes in the currently used model of IT resources management. The research was conducted in 134 SMEs companies, taking into consideration perception of mental barriers from the perspective of strategic level managers (CEO), tactical level managers and IT managers (CIO).

The rest of this paper is organized as follows: presentation of the notion and models of cloud computing, discussion concerning benefits of implementation of this solution and most often identified barriers of cloud computing implementation. Next the development of cloud computing in Poland was presented. As an introduction to presentation of research results and identification of mental barriers of cloud computing implementation the components of trust in cloud computing were presented. 


\section{Cloud COMPUTING}

There are many definitions of cloud computing, in which different aspects are underlined of this still new for some enterprises model of IT resources management. The technology is most often the key element of definition [12], some authors focus on the business model e.g. collaboration and pay-as-you-go [13] and the reduction in capital expenditure [14]]. Different authors have different opinions about the core conceptualizations of cloud computing. The reasons for these different opinions are as follows [15]:

- As an emerging IT service model, cloud computing has had only a relatively short lifetime in which to develop into a fully formed paradigm.

- Contributors to the development of cloud computing theory are extremely varied, both in terms of industry and academic background.

Grossman and $\mathrm{Gu}$ [16], described cloud computing as an infrastructure that provides resources or services over a network, often the Internet, usually at the scale and with the reliability of a data center.

Buyya et al. [17] defined cloud computing as a type of parallel and distributed system consisting of a collection of inter-connected and virtualized computers that are dynamically provisioned and presented as one or more unified computing resources based on service-level agreements established through negotiation between the service provider and consumers.

One of the most complex definition is provided by National Institute of Standards and Technology: cloud computing is a model for enabling ubiquitous, convenient, on-demand network access to a shared pool of configurable computing resources (e.g., networks, servers, storage, applications, and services) that can be rapidly provisioned and released with minimal management effort or service provider interaction [18]. This cloud model is composed of five essential characteristics, three service models, and four deployment models.

The most important characteristics include: on-demand self-service, broad network access, resource pooling, rapid elasticity, measured service [18].

Cloud services delivery models can be broadly categorized into three types: Infrastructure-as-a-service (IaaS), Platform-as-a-service (PaaS) and Software-as-aservice (SaaS). Each of the service types serve different purposes and target different customers however they share a common business model. The fundamental of the model is an offer of making accessible of their computing resources including services, applications, infrastructures, and platform to customers.

Infrastructure as a Service (IaaS) means using computer hardware via the Internet. IaaS is divided into Compute Clouds and Resource Clouds [19]. Compute Clouds provide access to computational resources such as CPUs, hypervisors and utilities. Resource Clouds contain managed and scalable resources as services to users.

Infrastructure as a Service model refers to the tangible physical devices (raw computing) like virtual computers, servers, storage devices, network transfer, which are physically located in one central place (data center) but they can be accessed and used over the Internet using the login authentication systems and passwords from any dumb terminal or device [10].

Platform as a Service (PaaS) is a more advanced level of cloud computing service than IaaS. PaaS provides a full or partial application development environment that enables developers to access resources for application development and to collaborate with others online.

Clouds and Resource Clouds [19]. Compute Clouds provide access to computational resources such as CPUs, hypervisors and utilities. Resource Clouds contain managed and scalable resources as services to users.

Infrastructure as a Service model refers to the tangible physical devices (raw computing) like virtual computers, servers, storage devices, network transfer, which are physically located in one central place (data center) but they can be accessed and used over the internet using the login authentication systems and passwords from any dumb terminal or device [10].

Platform as a Service (PaaS) is a more advanced level of cloud computing service than IaaS. PaaS provides a full or partial application development environment that enables developers to access resources for application development and to collaborate with others online.

By choosing a specific model of cloud computing the service user defines the division of control over the IT resources employed between himself and the service provider [20]. Division of control in cloud computing models was shown in Fig. 1.

In the traditional model the user has almost total control over the infrastructure and software he owns. However, in many cases his self-sufficiency is somewhat limited by the necessity to use Internet Service Providers.

In the IaaS model almost the entire substantial part of the IT infrastructure is outsourced. The user retains control over his data and software.

In the PaaS model the service provider also provides the service customer with the operating environments, where the user may operate the applications he installs.

In the SaaS model the entire infrastructure along with the software is under the control of the service provider. The user retains control over his data.

There are four different cloud deployment models within organizations namely [21],[10]:

1. Public cloud: It is available from a third party service provider via Internet and is very cost effective for SMEs to deploy IT solutions.

2. Private cloud: It is managed within an organization and is suitable for large enterprises (managed within the walls of the enterprises). (...) Private clouds provide the advantages of public clouds but still incur capital expenditures.

3. Community cloud: It is used and controlled by a group of enterprises, which have shared interests. For example, the US federal government using community cloud (built on Terremark's Enterprise cloud platform) for forms.gov, flu.gov, cars.gov, USA.gov, Apps.gov. 


\begin{tabular}{|c|c|c|c|}
\hline $\begin{array}{l}\text { Traditional } \\
\text { model } \\
\text { On-premise }\end{array}$ & $\begin{array}{c}\text { Infrastruc- } \\
\text { ture as a } \\
\text { Service } \\
\text { IaaS }\end{array}$ & $\begin{array}{c}\text { Platform } \\
\text { as a Service } \\
\text { PaaS }\end{array}$ & $\begin{array}{c}\text { Software } \\
\text { as a Service } \\
\text { SaaS }\end{array}$ \\
\hline Data & Data & Data & Data \\
\hline Application & Application & Application & Application \\
\hline $\begin{array}{c}\text { Runtime } \\
\text { environment }\end{array}$ & $\begin{array}{c}\text { Runtime } \\
\text { environment }\end{array}$ & $\begin{array}{c}\text { Runtime } \\
\text { environment }\end{array}$ & $\begin{array}{c}\text { Runtime } \\
\text { environment }\end{array}$ \\
\hline $\begin{array}{c}\text { Virtual } \\
\text { machine }\end{array}$ & $\begin{array}{c}\text { Virtual } \\
\text { machine }\end{array}$ & $\begin{array}{c}\text { Virtual } \\
\text { machine }\end{array}$ & $\begin{array}{c}\text { Virtual } \\
\text { machine }\end{array}$ \\
\hline Server & Server & Server & Server \\
\hline Data store & Data store & Data store & Data store \\
\hline Network & Network & Network & Network \\
\hline
\end{tabular}

Under control of the user
Under shared control
Under service provider control

Fig. 1. Division of control in cloud computing models [20]

4. Hybrid cloud: It is a combination of public and private cloud.

For many users handing over almost total control over their own IT resources is hard to accept and that is why the users very often decide to apply private or hybrid cloud model.

\section{Cloud Computing Benefits}

Cloud Computing will have a profound impact on the cost structure of all the industries using hardware and software, and therefore it will have significant impact on [22]:

- Business creation

- Macroeconomic performance

- Job creation in all industries

- Job reallocation in the ICT sector

- Public finance accounts, through direct impact on public sector spending and the indirect one on the tax revenues.

Data processing in the cloud gives new possibilities thanks to which organization uses its resources in a more costly effective and flexible way. Benefits may be considered in a three aspects:

- technical benefits,

- financial benefits,

- organizational benefits.

Technical benefits are perceived by the prism of flexible usage of computational power. In case of typical computing architecture with dedicated servers for every application the computational power of big and expensive computers is not used by most of the time. In a cloud computing shared resources are made accessible to those applications which require it at a given period of time. Thanks to this solution [23]:

- an access to computational resources for every application is growing,

- investments into hardware are limited with simultaneous decrease of time needed for computing purpose,

- computing power is allocated for those applications which currently need it,

- the constant level for access to services is maintained regardless of the number of users (scalability),

- there exist the possibility of fast acquisition of external computing power.

In case of cloud computing usage enterprises pay only for resources which were used.

Providers of cloud computing ensure for their customers access to the latest version of software (automatic upgrade) and SaaS.

Financial benefits contain most of all cost reduction (installation and maintenance) [14]. Cloud computing allows for decrease of costs connected with purchasing software licenses. Shorter time-to-market, means the possibility of faster introduction of product onto a market and achievement of financial benefits.

Organizational benefits embrace increase of flexibility and enterprise's openness on introduction of new solutions and increasing efficiency of its functioning. Its sources may be find in:

- limitation of backstage resources in a form of resources (external companies, IT).

- faster implementation of new business applications and IT solutions,

- transfer of the risk connected with IT infrastructure on the service provider,

- easier access to applications for mobile employees.

Summing up considerations concerning benefits of cloud computing application it is worth mentioning IDC research results [24]: demonstrable, tangible economic benefits are available from the adoption of cloud in the EU amongst enterprises. Based on the survey conducted for this study, that included 479 enterprises already using cloud for their businesses, $81 \%$ reported lower IT costs with a 10 to $20 \%$ reduction being typical, but $12 \%$ reported savings of $30 \%$ or more. Business benefits included more effective mobile working (46\%), higher productivity (41\%), more use of standard processes $(35 \%)$, better ability to enter new business areas (33\%) and the ability to open up in new locations (32\%) [24].

The main perceived benefits of the cloud computing model in SMEs were also the subject of The European Network and Information Security Agency research [25]. Fig. 2 shows the results of the study.

The costs savings are thought to be the most important benefits of cloud computing. $68 \%$ of SMEs specified that this solution would help to eliminate or minimize investments in IT infrastructure. Companies indicated that adjustment and flexibility of IT resources is also very 




Fig. 2. Benefits of cloud computing model in SMEs [25]

important for them (64\%), mostly due to the fact that the company do not need to handle software updates, new versions of products or any other necessary actions that should be undertaken to adapt systems to the changes in regulations (e.g. changes in tax rates). $53 \%$ of respondents supported opinion that cloud computing offers business operation continuity and permits data recovery. The remaining part of the respondents $(47 \%)$ is concerned with the efficiency of Internet connection, data transfer security and storage. The increase of computing power and business development (36\%) and the elimination of barriers to modernization of business processes (31\%) are not of a great importance to SMEs.

\section{BARRIERS IN Cloud COMPUTING ADOPTION}

The managers who consider the change of IT resources model management from traditional one to cloud computing model have numerous less or more justified fears. Identification of these barriers is a subject of many research and scientific discussions [20], [26],[10].

In research conducted by IDC analysts [24.] the impact of 12 identified barriers was showed. In the assessment of managers the barriers which have the strongest impact are: legal jurisdiction, security and data protection, trust, data access and portability, data location, local support, change control, ownership and customization, evaluation of usefulness, slow internet connection, local language and tax incentives. As it was showed in the cited report none of the barriers cannot be accepted as the only most important one which was mentioned by most of respondents. There can be distinguished six strongly correlated barriers which are acknowledged as the most significant ones by $62 \%$ of respondents. They are: legal jurisdiction, security and data protection, trust, data access and portability, data location, local support [24.].

The relevance of the barriers to the cloud computing implementation was presented in Figure 3.

There are also interesting research results [26], where cloud computing providers were the respondents. Providers

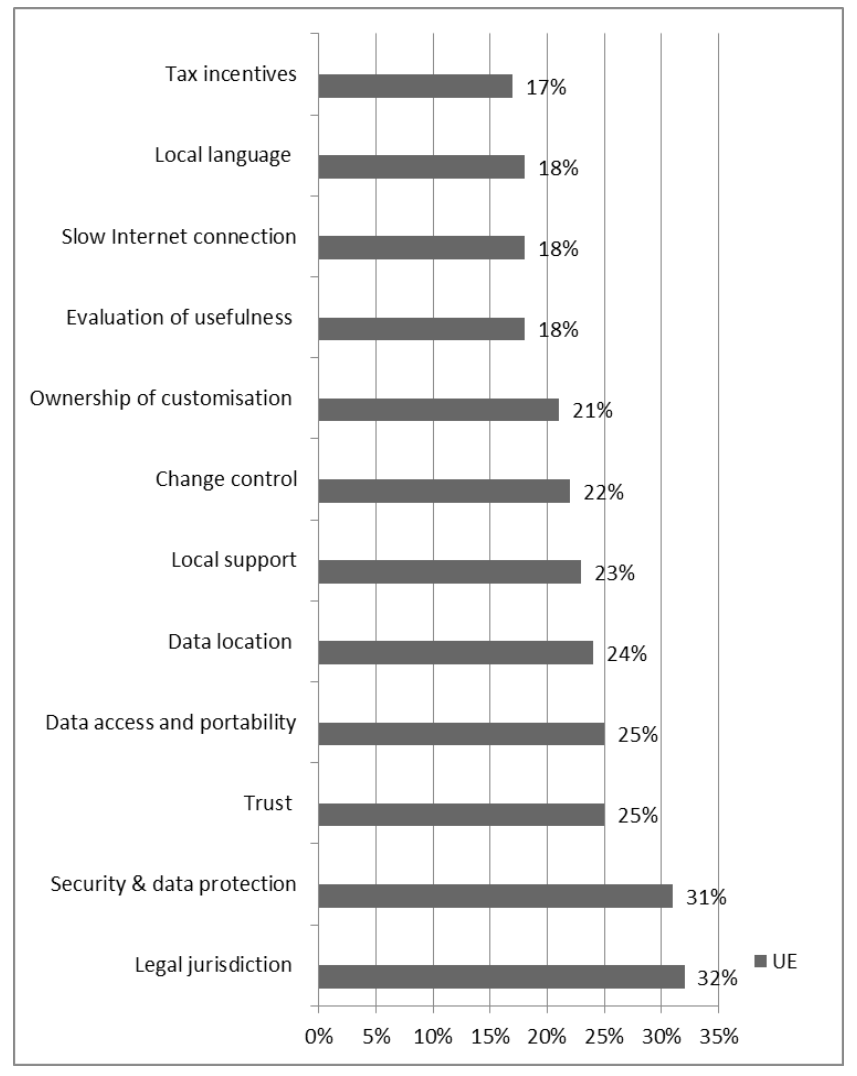

Fig. 3. The relevance of the barriers to the cloud computing implementation [24]

say that customers' main concern over switching to cloud is losing control - an issue voiced by almost half of all respondents (48\%). As well, $39 \%$ say that data loss and privacy risks are a major worry. Worries of $41 \%$ customers concerned integration with existing architecture, a $28 \%$ were not sure the promise of cloud environment can be realized, $28 \%$ claimed that implementation of integration costs is too high, $27 \%$ worried of risk of intellectual property theft and lack of legal and regulatory compliance $22 \%$.

Companies are afraid that their IT performance is controlled not by their own staff but by off-premises cloud providers; and that they may not be able to make necessary changes in application features easily and when needed [27].

Security concerning in particular privacy and data confidentiality, is one of the most cited objections to cloud computing [28].

In the light of above research in order to ensure cloud computing development technical, legal, organizational and mental barriers should be removed in the highest possible degree.

\section{V.Development Of Cloud Computing In Poland}

According to Business Software Alliance [29.] Poland takes $12^{\text {th }}$ place among 24 countries in the ranking of government policies having influence on development of cloud computing. This ranking evaluates status in 24 countries, which are together responsible for 80 percent of world IT and communication resources and the policy of 
these countries in 7 basic areas: data protection, security in cyberspace, cyber-crime, intellectual property, technological interoperatibility and law harmonization, free trade and IT infrastructure.

5 top places in the ranking were achieved by: Japan, Australia, Germany, USA and France.

Macroeconomics factors which positively influence on such high position of Poland are most of all [29]:

- good legal regulations in the scope of privacy protection, electronic signature, e-commerce, and cyber-crime which constitute a basis for building trust for cloud computing technology.

- Poland also possesses one of the most comprehensible systems of intellectual property protection. In 2008 legal regulations were amended in the scope of Internet provider responsibilities.

- Polish government promotes innovations and interoperatibility and apply non discriminating policy in the scope of governmental orders.

The factor influencing negatively on the position of Poland is still limited access to broadband Internet comparing to such countries as Germany or Japan.

Among microeconomics factors technological preferences of IT (CIO) managers have a big influence on implementation of cloud computing in Polish enterprises. In the table 1 were presented research results on the sample of 3000 (CIO) managers [30].

TABLE I.

TECHNOLOGICAL PREFERENCES OF IT CIO MANAGERS IN THE WORLD AND IN POLAND

\begin{tabular}{|l|c|c|c|}
\hline \multicolumn{1}{|c|}{ Category } & $\begin{array}{c}\text { Global } \\
2009\end{array}$ & $\begin{array}{c}\text { Global } \\
2011\end{array}$ & $\begin{array}{c}\text { Poland } \\
2011\end{array}$ \\
\hline $\begin{array}{l}\text { Cloud } \\
\text { Computing }\end{array}$ & $33 \%$ & $60 \%$ & $49 \%$ \\
\hline $\begin{array}{l}\text { Mobile } \\
\text { solutions }\end{array}$ & $68 \%$ & $74 \%$ & $76 \%$ \\
\hline Virtualization & $75 \%$ & $68 \%$ & $81 \%$ \\
\hline
\end{tabular}

Presented in the table 1 research results indicate that technological preferences of CIO IT managers in Poland are strongly directed at virtualization $(81 \%)$ and the application of mobile solutions $(76 \%)$ and exceed percentage values in a global scale. Preferences in implementation of cloud computing model $(49 \%)$ are lower than values in a global scale $(60 \%)$, but comparatively to other countries are high.

Identification, analysis and trial of assessment of the rest factors having influence on development of cloud computing in Polish SMEs, with special consideration of factors having negative influence (barriers) will be presented in the next points.

\section{Mental BarRiers ANd COMPONENTS OF TRUST IN Cloud COMPUTING}

Many researchers claim that among barriers of cloud computing implementation the central place should belong to mentality, which can be in favor of open attitudes towards changes or it can constitute crucial barrier.

Swida-Zieba [31] defines mentality as a structure resistant to changes, deeply rooted, non verbalized and subliminal. It constitutes the result of the whole of socialization: system of situational incentives, own experiences, perception of reality and influence of education processes. It is formal and generalized structure, conditioning involuntary and spontaneous reactions on incentives and situations [31].

Mentality of managers is shaped in the process of interaction of many factors from social environment and their own experiences and in the future it has influence on their attitudes, leadership styles or undertaken decisions.

Mental barriers of managers manifest in natural perception reactions e.g. ,cloud computing will not bring any benefits for the company”, emotional e.g. „we do not trust cloud computing model” and behavioral e.g.. „cloud computing is not needed in the company and we are not going to implement it".

To best mitigate barriers to confidence, we need to understand the main components affecting cloud trust [32]:

- Security,

- Privacy,

- Accountability,

- Auditability

Security mechanisms (e.g. encryption) which make it extremely difficult or uneconomical for an unauthorized person to access some information [32].

Privacy - protection against the exposure or leakage of personal or confidential data (e.g. personally identifiable information (PII)) [33].

Accountability - the obligation and/ or willingness to demonstrate and take responsibility for performance in light of agreed-upon expectations, accountability goes beyond responsibility by obligating an organization to be answerable for its actions [32], [33].

Auditability - the relative ease of auditing a system or an environment. Poor auditability means that the system has poorly-maintained (or non-existent) records and systems that enable efficient auditing of processes within the cloud [32]. Auditability enables review of undertaken activities and stating responsibilities of persons (employees) or organization for undertaken activities, especially when they were not compliant with stated security policy.

Mental barriers are constituted also by insufficient knowledge of managers concerning notion of cloud computing, its advantages and disadvantages and risk connected with implementation of this solution. The current state of managers' knowledge on cloud computing is hardly to categorize as satisfactory one [20]. It causes ungrounded worries about: data location and connected with it data access and portability.

Managers very often do not perceive the needs of changes of current model of IT resources management for cloud computing model, because they assess its usability very low and the risk of introduction of changes is assessed very high. 


\section{MENTAL BARRIERS TO ADOPTION ClOUd COMPUTING. RESEARCH RESULTS}

In Poland exist $1.9 \mathrm{mln}$ of enterprises, and over $1,8 \mathrm{mln}$ is constituted by microenterprises (employing up to 9 employees), 55 thousand small enterprises (employing from 10 to 49 employees), 15 thousand medium sized enterprises (employing from 50 to 249 employees and 3,2 thousand of big enterprises (above 250 employees).

As far as research methodology is concerned it is worth mentioning that the study in the light of the above was carried out on the sample of 134 companies which are not representative to the entire Polish SME sector. Nevertheless in the authors' opinion, the results are an interesting attempt of building the image of Polish SMEs, which face the challenge of cloud computing implementation.

The aim of conducted research was to verify the following research hypotheses:

H1: Among mental barriers the biggest worries are connected with lack of trust for cloud computing model.

H2: Mental barriers connected with insufficient knowledge are not perceived by managers as ,high barrier”.

H3: Between "level of management" and perception of highlighted mental barriers occurs stochastically essential dependence.

The study involved: 80 micro-enterprises, 42 smallenterprises and 10 medium-enterprises from the following sectors: manufacturing - 39, trade - 65 and services -30 .

The study was conducted in January - February 2014 with the use of electronic questionnaire. Link to the survey was provided via email sent to the companies. Questionnaire return rate was $27 \%$. In the research participated: 54 managers of strategic level, 48 managers of tactical level and 32 IT CIO's. The results of a few chosen survey questions are presented below.

In order to examine the relevance of each barrier to the cloud computing implementation decision, twelve questions from IDC report [24] research carried out on the sample of European enterprises were used.

- Security \& data protection: "We are worried about the security and data protection guaranteed by cloud services"

- Trust: "It is difficult to judge which cloud services are"

- Data location: "We do not know and/or cannot control the location of our corporate data"

- Local support: "There is no local support for the services"

- Change control: "We cannot control software changes and upgrades made by the vendor"

- Ownership of customization: "We do not know who owns the customizations/changes we make to the cloud services"

- Evaluation of usefulness: "We do not know how to evaluate the usefulness of cloud service for our organization"

- Slow Internet connection: "Our Internet connection(s) is/are not reliable or fast enough"
- Local language: "There is no local language version of the services"

- Tax incentives: "Tax and other incentives make buying with capital more attractive than paying for what we use on subscription"

- Legal Jurisdiction: "If we have a dispute with the cloud service provider, I may have to go to court in another country inside the EU"

- Data Access and Portability ""Concern about our ability to move data from one vendor to another or onto our own IT"

Respondents rated each response on a scale: low barrier, average barrier, high barrier. Next all the barriers were grouped into three groups: mental, technical and legal barriers. In the opinion of respondents mental barriers are more frequent than technological or legal barriers perceived as a strong obstacle in the decision on whether or not to implement cloud computing solutions. Among all responses "high barrier" was indicated by as much as 38\% of responses related to the mental barriers, $33 \%$ to the technical barriers and $29 \%$ to the legal barriers.

The next question involved more specific identification of mental barriers.

For the assessment of lack of trust barrier were used questions concerning: security and data protection, privacy, accountability and auditability. In the assessment of

TABLE II.

THE ASSESSMENT OF MENTAL BARRIERS INFLUENCE ON CLOUD COMPUTING ADAPTION

\begin{tabular}{|l|c|c|c|}
\hline & low barrier & $\begin{array}{c}\text { medium } \\
\text { barrier }\end{array}$ & high barrier \\
\hline & \multicolumn{3}{|c|}{ Trust } \\
\hline $\begin{array}{c}\text { Security and } \\
\text { data } \\
\text { protection }\end{array}$ & 32 & 54 & 47 \\
\hline $\begin{array}{l}\text { Privacy } \\
\text { Accountabilit } \\
\text { y }\end{array}$ & 53 & 50 & 51 \\
\hline $\begin{array}{l}\text { Auditability } \\
\text { Luck }\end{array}$ & 51 & 40 & 38 \\
\hline $\begin{array}{l}|c| \\
\text { Lack of knowledge } \\
\text { and } \\
\text { portability }\end{array}$ & 29 & 64 & 40 \\
\hline $\begin{array}{l}\text { Data location } \\
\text { access }\end{array}$ & 19 & 70 & 46 \\
\hline $\begin{array}{l}\text { Evaluation of } \\
\text { usefulness }\end{array}$ & 50 & 57 & 27 \\
\hline
\end{tabular}


insufficient knowledge barrier cloud computing model the respondents' answers concerning: data location and data access and portability were evaluated. In the assessment of lack of the need of change of IT resources model evaluation of usefulness was used.

In the table II was presented evaluation of mental barriers' influence on cloud computing adaptation.

In the table II the greatest number of „high barrier” indication obtained: privacy (51) and ,security and data protection" (47). It means that respondents as the most important barrier perceive ,lack of trust" for cloud computing.

Hypothesis H1 was positively verified.

The barriers connected with the lack of knowledge were most often assessed as ,medium barrier”, what confirmed rightness of $\mathrm{H} 2$ hypotheses.

In the further considerations ,high barrier" indications of respondents were only taken into account. For ,trust” barrier the number of ,high barrier” indications was summed up for four analyzed of such components as: security and data protection, privacy, accountability and auditability. For „lack of knowledge" „high barrier" indications were summed up for data location and data access and portability.

In the correlation table presented in table III the responses of strategic, tactical and IT CIOs level managers were taken into account.

TABLE III.

CORRELATION TABLE

\begin{tabular}{|c|c|c|c|c|}
\hline & Trust & $\begin{array}{c}\text { Lack of } \\
\text { know- } \\
\text { ledge }\end{array}$ & $\begin{array}{c}\text { Lack of } \\
\text { the need }\end{array}$ & $\begin{array}{c}\text { Sum- } \\
\text { mary }\end{array}$ \\
\hline $\begin{array}{c}\text { Strategic } \\
\text { managers }\end{array}$ & $\begin{array}{c}108 \\
(93,79)\end{array}$ & $\begin{array}{c}36 \\
(45,06)\end{array}$ & $\begin{array}{c}9 \\
(14,15)\end{array}$ & 153 \\
\hline $\begin{array}{c}\text { Tactical } \\
\text { Managers }\end{array}$ & $\begin{array}{c}52 \\
(66,82)\end{array}$ & $\begin{array}{c}44 \\
(32,10)\end{array}$ & $\begin{array}{c}13 \\
(10,08)\end{array}$ & 109 \\
\hline $\begin{array}{c}\text { IT } \\
\text { (CIO) }\end{array}$ & $\begin{array}{c}19 \\
(18,39)\end{array}$ & $\begin{array}{c}6 \\
(8,84)\end{array}$ & $\begin{array}{c}5 \\
(2,77)\end{array}$ & 30 \\
\hline & 179 & 86 & 27 & 292 \\
\hline
\end{tabular}

In the correlation table quantities of indications were placed as well as numerical strengths in parentheses. Using the chi-square independence test $\left(\chi^{2}\right)$ we test the H0 hypothesis: concerning independence of investigated features in face of alternative H1 hypothesis: features are not independent.

This statistics has $\chi^{2}$ out of $(\mathrm{r}-1)(\mathrm{k}-1)$ layout of the degrees of freedom, where $\mathrm{r}$ - the number of columns, $\mathrm{k}$ - the linage. The calculated value of the statistics $\chi^{2}=17,11$, the value from tables for $\chi^{2}=0,05$ and 4 degrees of freedom $\chi_{\alpha}^{2}$ $=9,45$. Therefore the following condition is fulfilled: $\chi^{2}=17,11>\chi_{\alpha}^{2}=9,45$ and the hypothesis $\mathrm{H} 0$ can be rejected. This means that between the type of manager and perception of mental barriers connected with trust, lack of knowledge or evaluation of usefulness the stochastic dependence occurs.

For the measurement of the power of correlations of examined variable the coefficient of Czuprow convergence (T) was used. This coefficient accepts values from the $[0,1]$ range. The nearer to the zero the coefficient of convergence is the dependence between variables is weaker. The calculated value of coefficient of convergence $T=0,17$ means that the dependence is weak, but statistically essential.

The obtained results allowed for positive verification of H3 hypothesis.

\section{VIII.CONCLUSION}

Presented research results among SMEs allowed to formulate the following conclusions:

1. Among mental barriers the biggest worries are connected with the lack of trust for cloud computing model.

2. Mental barriers connected with insufficient knowledge are not perceived by managers as ,high barrier”.

3. Between "level of management" and perception of distinguished mental barriers stochastically essential dependence occurs.

4. The trust as a high barrier was most often indicated by strategic level managers.

5. Lack of knowledge concerning cloud computing was most often assessed as ,high barrier" by managers of tactical level.

6. IT CIOs recognize advantages of cloud computing model and very rarely assess "lack of implementation need" as ,high barrier".

The key for liquidation of mental barriers rebounding negatively on attitudes of managers in the face of decision concerning implementation of cloud computing model can be consciously shaped program of general education, and the assurance of instruments by means of which it will be implemented. Operations should be directed at the wide formation of features and social competences, favoring open to changes attitudes. Not flexible enough attitudes of managers and management of specific levels, anxiety of undertaking risk and lack of interest in new solutions are consequences of low level of the needs understanding of modern information society.

\section{REFERENCES}

[1] „Sizing The Cloud”, http://www.forrester.com/Sizing+The+Cloud /fulltext/-/E-RES58161 (accessed on: 1 April 2014).

[2] Q. Li, C. Wang, J. Wu, J. Li, Z.-Y. Wang, "Towards the businessinformation technology alignment in cloud computing environment: An approach based on collaboration points and agents". International Journal of Computer Integrated Manufacturing, vol. 24, no. 11, pp. 1038-1057, November 2011.

[3] R. King, "Cloud computing: Small companies take flight". BusinessWeek Online, 4, 2008. http://www.businessweek.com/ technology/content/aug2008/tc2008083 619516.htm (accessed on: 1 April 2014)

[4] C. Russell, F. Jeff, J. Norm, M. Seanan, P. Carolyn, S. Patrick, J. Stanley, "Cloud Computing in the Public Sector: Public Manager"s 
Guide to Evaluating and Adopting Cloud Computing", Cisco Internet Business Solutions Group 2009.

[5] C. Tsaravas, M. Themistocleous, "Cloud Computing and eGovernment: a Literature Review", European, Mediterranean \&Middle Eastern Conference on Information Systems, Greece, pp. 154-164, 2011.

[6] D. Jelonek, C. Stępniak, T. Turek, "The Concept of Building Regional Business Spatial Community". In: ICETE 2013. 10th International Joint Conference on e-Business and Telecommunications. Proceedings. 29-31 July 2013, Reyklavik, Iceland 2013.

[7] N. Sultan, "Cloud computing for education: A new dawn?" International Journal of Information Management, vol. 30, pp. 109116,2010

[8] N. Sultan," Making use of cloud computing for healthcare provision: Opportunities and challenges", International Journal of Information Management, vol. 34, pp. 177-184, 2014

[9] E. Savitz, W. Vogels, "How the cloud changes businesses big and small”. Forbes.com, vol. 14, 2012.

[10] P. Gupta, A. Seetharaman, J. R. Raj, "The usage and adoption of cloud computing by small and medium businesses", International Journal of Information Management, vol. 33, pp. 861-874, 2013.

[11] S. Mahesh, B. J. L. Landry, T. Sridhar, K. R. Walsh, "A decision table for the cloud computing decision in small business". Information Resources Management Journal, vol. 24, no. 3, pp. 9-25, JulySeptember 2011.

[12] M. Armbrust, A. Fox, R. Griffith, A. Joseph, R. Katz, "Above the Clouds: A Berkeley View of Cloud Computing", Technical report No. UCB/EECS-2009-28 University of California at Berkley, USA, 2009.

[13] W. Kim, "Cloud computing: Today and tomorrow". Journal of Object Technology, vol. 8, no. 1, pp. 65-72, 2009.

[14] S. Bhardwaj, L. Jain, and S. Jain, "Cloud computing: A study of infrastructure as a service", International Journal of engineering and information Technology, vol.2, no. 1, pp.60-63, 2010.

[15] C. Madhavaiah, I. Bashir, S. I. Shafi, "Defining Cloud Computing in Business Perspective: A Review of Research", MDI SAGE Publications, Vision, vol. 16, no. 3, pp.163-173, 2012.

[16] R. L. Grossman, Y. Gu, "On the varieties of clouds for data intensive computing". IEEE Computer Society Bulletin of the Technical Committee on Data Engineering, vol.32, no. 1, pp. 44-51, 2009.

[17] R. Buyya, C. S. Yeo, S. Venugopal, "Market-oriented cloud computing: Vision, hype and reality for delivering IT services as computing utilities". Proceedings of the 10th IEEE International Conference on High Performance Computing and Communications, Dalian, China, 25-27 September 2008.
[18] P. Mell, T. Grance, "The NIST Definition of Cloud Computing. Recommendations of the National Institute of Standards and Technology", NIST Special Publication 800-145, September 2011.

[19] V. Chang, R. J. Walters, G. Wills," The development that leads to the Cloud Computing Business Framework", International Journal of Information Management, vol. 33, pp. 524-538, 2013.

[20] "Cloud computing: Flexibility, Efficiency, Security". Report ThinkTank, Microsoft 2011.

[21] S. Marston, Z. Li, S. Bandyopadhyay, J. Zhang, and A. Ghalsasi,. "Cloud computing-The business perspective". Decision Support Systems, vol. 51, no. 1, pp. 176-189, April 2011.

[22] F. Etro, "The economics of cloud computing". IUP Journal of Managerial Economics, vol. 9, no. 2, pp. 7-22, 2011

[23] "Cloud Computing in financial sector", Report Banking Technologies Forum at Polish Bank Union 2013.

[24] Quantitative Estimates of the Demand for Cloud Computing in Europe and the Likely Barriers to Up-take, SMART 2011/0045, D4- Final Report, IDC, 2012

[25] "An SME perspective on Cloud Computing. Survey", The European Network and Information Security Agency (ENISA), November 2009. http://www.enisa.europa.eu/ (accessed on: 10 March 2014).

[26] KPMG International's 2012 Global Cloud Providers Survey,

[27] N. Leavitt, "Is cloud computing really ready for prime time?" Computer, vol. 42, no. 1, pp.15-20, 2009.

[28] Q. Zhang, L. Cheng, R. Boutaba, "Cloud computing: State-of-theart and research challenges", Journal of Internet Service Application, vol. 1 , no. 1 , pp. 7-18, 2010

[29] "2013 BSA Global Cloud Computing Scorecard. A Clear Path to Progress", BSA The Software Alliance: IBM CIO Study 2011

[30] . "The Essential CIO. Insights from the Global Chief Information Officer Study", IBM Institute for Business Value, 2011.

[31] H. Swida-Zieba, Mechanisms of social enslavement Reflections at the decline of formations., The University of Warsaw, Warsaw 1990.

[32] R. K L Ko, P. Jagadpramana, M. Mowbray, S. Pearson, M. Kirchberg, Q. Liang, B. S. Lee, "TrustCloud: A Framework for Accountability and Trust in Cloud Computing", The 2nd IEEE Cloud Forum for Practitioners (IEEE ICFP 2011), Washington DC, USA, July 7-8, 2011.

[33] . S. Pearson and A. Charlesworth, "Accountability as a way forward for privacy protection in the cloud," Cloud Computing, 2009, pp. 131144. 